Journal of Applied Pharmaceutical Science Vol. 6 (03), pp. 048-050, March, 2016

Available online at http://www.japsonline.com

DOI: $10.7324 / J A P S .2016 .60308$

ISSN 2231-3354 (cc)) BY-NC-SA

\title{
Non-Albicans Candiduria: An Emerging Threat
}

\author{
Rahul Kumar Goyal, Hiba Sami*, Vashishth Mishra, Rajesh Bareja, Rabindra Nath Behara \\ Department of Microbiology, Shri Ram Murti Smarak Institute of Medical Sciences, Bareilly, India.
}

\begin{tabular}{l}
\hline ARTICLE INFO \\
\hline Article history: \\
Received on: 04/01/2016 \\
Revised on: 08/02/2016 \\
Accepted on: $22 / 02 / 2016$ \\
Available online: $30 / 03 / 2016$ \\
\hline Key words: \\
Non Albicans Candida, UTI, \\
Candiduria.
\end{tabular}

Candiduria.

\begin{abstract}
Objective: The incidence of Candida has been on rise worldwide. Clinicians face dilemma in differentiating colonization from true candiduria. The species identification of Candida is important, as non albicans Candida species are increasing in number and more resistant to antifungal drugs.

Material and methods: The present study was conducted at a tertiary care teaching hospital of North India with an aim of investigating prevalence of NAC spp. among Candida isolates from urinary tract specimens.

Results: A total of 7627 urine samples were analysed in a tertiary care hospital. The Candida isolates (180) were further speciated by Gram stain, culture on sabouraud's dextrose agar, germ tube test, sugar fermentation test. A total of 180 (2.36\%) Candida species were isolated from 7627 urine samples. Among them non albicans Candida species were predominant $(66.7 \%)$, compared to Candida albicans $(33.3 \%)$. The rate of isolates of Candida species were more in females, $101(56.1 \%)$ than in males $79(43.9 \%)$. The highest isolation rates of Candida among uropathogens were found in age group above 60 years. The emergence of non-albicans Candida similar to the trends in the western countries should be a cause of concern in our country.

Conclusions: NAC spp. have emerged as an important cause of urinary tract infections. Its isolation from clinical specimens can no longer be ignored as nonpathogenic isolate nor can it be dismissed as a contaminant. Proper surveillance of these fungal pathogens is important to improve quality of care in tertiary care setting.
\end{abstract}

\section{INTRODUCTION}

Urinary tract infections (UTIs) are amongst the most common infections in both outpatients as well as hospitalised patients (Rashedmarandi et al., 2008). The frequency of urinary tract infections (UTIs) due to Candida species is increasing and these infections are now being the most common clinical finding, particularly in hospitalised patients (Manisha et al., 2011). Candida species account for almost 10-15\% nosocomial UTIs (Lundstrom et al., 2001; Kauffman et al., 2000). The presence of Candida species in the urine is known as candiduria. Candiduria if not properly diagnosed and treated has been source of morbidity and mortality (Manjunath et al., 2011). Non albicans Candida (NAC) species have replaced Candida albicans as the

\footnotetext{
* Corresponding Author

Dr Hiba Sami, Assistant Professor, Department of Microbiology, SRMSIMS, Bareilly, India. Email:hibasamizafar[at]gmail.com
}

predominant pathogen. Non albicans Candida species appear better adopted to the urinary tract environment and are more resistant to antifungal drugs compared to $C$. albicans. The clinical manifestations of infections caused by different members of NAC spp. are usually indistinguishable but several NAC species are inherently resistant or acquire resistance or both to commonly used antifungal drugs (Manjunath et al., 2011).

The shift of Candida spp. from commensal to potent pathogen is facilitated by a number of virulence factors such as adherence to host tissues and medical devices, biofilm formation, and secretion of extracellular hydrolytic enzymes (Sardi et al., 2013). Although there has been extensive research to identify these pathogenic attributes in $C$. albicans, relatively less is known about NAC spp (Sachin et al., 2012).

The present study was conducted at a tertiary care teaching hospital of North India with an aim of investigating prevalence of NAC spp. among Candida isolates from urinary tract specimens. 


\section{MATERIALS AND METHODS}

A total of 7627 urine samples were collected from patients attending to outpatient department and admitted in the hospital at SRMSIMS, Bareilly from June 2014 to June 2015. Permission from the institutional ethical committee was taken.

\section{Inclusion criteria}

Male and female patients of all age groups were considered for our study. Both outpatients and inpatients who presented with signs and symptoms of urinary tract infections were included. Pure growth of yeast isolates with significant colony count was included in the study.

\section{Exclusion criteria}

The urine samples where Candida species was isolated in the absence of pyuria, Candida with colony count $\leq 1000 \mathrm{CFU} / \mathrm{ml}$ and mixed growth (polymicrobial growth) were excluded from analysis.

The urine samples were collected in a sterile leak proof container with screw capped lids and transported immediately to microbiology laboratory. Urine wet mount examination was done to look for the presence of pus cells, red blood cells, casts, crystals or any bacterial or fungal elements. The urine samples were inoculated on Cysteine Lactose Electrolyte Deficient (CLED) by calibrated wire loop technique delivering $0.001 \mathrm{ml}$ of urine as per standard protocol for urine culture. The culture plates were incubated aerobically at $37^{\circ} \mathrm{C}$ for 24 to 48 hours. Candida species isolated on culture plates with colony count $>10000 \mathrm{CFU} / \mathrm{ml}$ were considered significant (Ang et al., 1993; Chakrabarthi et al., 2002).

The Candida isolates (180) were further speciated by culture on Sabourauds dextrose agar (SDA) in accordance with the standard methods. They were further speciated on the basis of colony characteristics, germ tube production, morphology on corn meal agar, HiCrome Candida agar (Hi Media), urease test, carbohydrate fermentation tests and assimilation tests using yeast nitrogen base agar and other tests as per standard recommended procedures (Forbes et al., 2002; Koneman et al., 1997; Moore et al., 1979).

\section{Germ tube test (GTT)}

This was done according to the method of Baker (1967) (Baker et al., 1967). Yeast isolates suspected to be $C$. albicans were inoculated into human serum, incubated for about $30 \mathrm{~min}$ at $37^{\circ} \mathrm{C}$ and examined microscopically for the production of germ tubes.

\section{RESULTS AND DISCUSSION}

A total of $180(2.36 \%)$ samples showed the growth of Candida species out of 7627 urine samples. Among them Non albicans Candida species 120 (66.7 \%), were predominant compared to $C$. albicans $60(33.3 \%)$. Non albicans Candida species included C. tropicalis (20.6\%), C. gullermondi (15.5\%), C. intermedia (15\%), C. krusei (11.1), C. pseudotropicalis (3.9) and C. stelloidia (0.5) [Table 1]. The rate of isolates of Candida species were more in females, $101(56.1 \%)$ than in males 79 (43.9\%). The highest isolation rates of Candida among uropathogens were found in age group above 60 years [Table 2].

Table 1: Distribution of Candida species in urine samples.

\begin{tabular}{lcc}
\hline Candida species & Total number $\mathbf{~ 1 8 0}$ & Percentage $(\boldsymbol{\%})$ \\
\hline C. albicans & 60 & 33.3 \\
C. tropicalis & 37 & 20.6 \\
C. krusei & 20 & 11.1 \\
C. gullermondi & 28 & 15.5 \\
C. intermedia & 27 & 15 \\
C. pseudotropicalis & 7 & 3.9 \\
C. stelloidia & 1 & 0.5 \\
\hline
\end{tabular}

Table 2: Age and Gender wise distribution of Candida isolates.

\begin{tabular}{cccc}
\hline Age group & Male & Female & Total \\
\hline $1-15$ & 3 & 4 & $\mathbf{7}$ \\
$16-30$ & 13 & 31 & $\mathbf{4 4}$ \\
$31-45$ & 10 & 19 & $\mathbf{2 9}$ \\
$46-60$ & 17 & 13 & $\mathbf{3 0}$ \\
$>60$ & 36 & 34 & $\mathbf{7 0}$ \\
\hline
\end{tabular}

The prevalence of candiduria caused by the species other than $C$. albicans was surprisingly high in the given study. Changing trends in the aetiopathogenesis of urinary tract infections and considerable increase in number of non albicans Candida species is a matter of concern (Ochipinti et al., 1994). In the present study, isolation rate of Candida species from urine samples were $2.36 \%$, which is comparable to the observation of Yashavanth et al., (2.27\%) (Yashavanth et al., 2013) and slightly higher than the observation of Ragini et al., (1.37\%) (Ragini et al., 2012). Studies have shown that there is considerable increase in non albicans Candida species among candiduria. Similar to the finding of Iman et al., (Iman et al., 2012) and Yashavanth et al., (Yashavanth et al., 2013), we found the isolation rate of non albicans Candida was $66.7 \%$, which is higher than $C$. albicans $33.3 \%$. This is also consistent with emergence of predominance of nonalbicans Candida species all over the world (Pfaller et al., 1999). Identification of Candida species is important as non albicans Candida are more resistant to azoles compared to that of C. albicans. C. krusei is intrinsically resistant to fluconazole.

The present study had a female preponderance, with an overall male: female ratio being 1:1.28, indicating that female sex is a risk factor for developing candiduria. Since colonization of vulvo vestibular area with Candida spp. is frequent in females, they are more at risk of developing candiduria due to ascending infection (Lundstrom et al., 2001; Bukhary et al., 2008). Though candidiasis can occur at all ages, we found the highest incidence of candiduria in the age group above $60 \mathrm{yrs}$ which is similar to as stated by Yashavanth et al. (Yashavanth et al., 2013). This could be due to lowered host defenses at extremes of age. This finding is supported by many other researchers. (Passos et al., 2005; Fisher et al., 1995; Kobayashi et al., 2004).

Among the Non albicans candida, C. tropicalis (20.6\%) was the most common followed by $C$. gullermondi $(15.5 \%)$. Our observation is similar to that of Álvarez-Lerma et al. (2003) and 
Kauffmann et al. (2005), where $>50 \%$ of urinary Candida isolates belonged to the above written species. NAC spp. are not only well adapted to the urinary tract but also more difficult to eradicate than C. albicans. Presence of indwelling urinary catheters, advanced age, diabetes mellitus, and pregnancy are major risk factors associated with candiduria. Incidence of candiduria was high among patients admitted to the ICU and among those who had a previous history of treatment with antibiotics (Sachin et al., 2014).

\section{CONCLUSION}

The emergence of non-albicans Candida similar to the trends in the western countries should be a cause of concern in our country. In our study, NAC spp. were the predominant pathogens associated with candiduria. Therefore, it can be concluded that NAC spp. have emerged as an important cause of urinary tract infections. Its isolation from clinical specimens can no longer be ignored as nonpathogenic isolate nor can it be dismissed as a contaminant. Proper surveillance of these fungal pathogens is important to improve quality of care in tertiary care setting.

\section{REFRENCES}

Alvarez-Lerma F, Nolla-Salas J, Leon C, et al.Candiduria in critically ill patients admitted to intensive care medical units. Intensive Care Med, 2003;29:1069-76.

Ang BSP, Talenti A, King B, Steekelberg JM, Wilson WR. Candidaemia from a urinary tract source: Microbiological aspects and clinical significance. Clin Infect Dis., 1993; 17 (4): 626-66.

Baker FJ (1967). Handbook of bacteriological technique, 2nd ed.Butterworth and Co. Ltd., London.

Bukhary ZA. Candiduria: A review of clinical significance and management. Saudi J Kidney Dis Transpl, 2008;19:350-60

Chakrabarthi A, Mohan B, Shrivastava SK, Marak RSK, Ghosh

A, Ray P. Change in the distribution and antifungal susceptibility of Candida species isolated from candidaemia cases in a tertiary care centre during 1996-2000. Ind. J. Med. Res., 2002; 116:5-12.

Fisher JF, Newman CL, Sobel JD. Yeast in the urine: Solution for a budding problem. Clin Infect Dis, 1995;20:183-9.

Forbes, B.A., Sahm, D.F., Weissfeld, A.S. 2002. Laboratory methods in basic mycology. In: Bailey and Scott $\mathrm{s}$ Diagnostic Microbiology, 11 th edn., Mosby, St Louis. Pp. 711-798

Iman KB, Shorouk KEH, Muhmoud M. Candida infection associated with urinary catheter in critically ill patients. Identification, antifungal susceptibility and risk factors. Res.J. of Med \& Med sciences, 2010; 5(1):79-86.

Kauffman CA, Vazquez JA, Sobel JD, Gallis HA, McKinsey DS, Karchmer AW, et al. Prospective multicenter surveillance study of funguria in hospitalised patients. Clin Infect Dis 2000; 30:14-18.

Kauffman CA. Candiduria. Clin Infect Dis 2005;41:S371-6.

Kobayashi CC, de Fernandes OF, Miranda KC, de Sousa ED, Silva Mdo R.Candiduria in hospital patients: A study prospective. Mycopathologia, 2004;158:49-52

Koneman, E.W., Allen, S.D., Janda, W.M., Schreckenberger, P.C. 1997. Mycology. In: Color Atlas and Textbook of Diagnostic
Microbiology, 5th edn. Lippincott Williams \& Wilkins, Philadelphia, PA. Pp. 983-1057.

Lundstrom T, Sobel J. Nosocomial candiduria: A review. Clin Infect Dis, 2001;32:1602-07.

Manisha J, Vinita D, Bibhabati M, Archana T, Poonam SL, Aradhana B. Candiduria in catheterized intensive care unit patients: Emerging microbiological trends. Ind. J.Path. Micro, 2011; 54(3): 552-55.

Manjunath GN, Prakash R, Vamseedhar A, Kiran S. Changing trends in the of antimicrobial drug resistance pattern of uropathogens isolated from hospitals and community patients with urinary tract infections in Tumkurand Bangalore. Int J Biol Med Res, 2011; 2(2):50407

Moore, G.S., Jaciow, D.M. 1979. Mycology for the Clinical Laboratory. Prentice- Hall, Reston, VA.

Ochipinti DJ, Gubbins PO, Schreckenberger P, Danziger LH. Frequency pathogenicity and microbiologic outcome of Non Candida albicanscandiduria. Europ J ClinMicrobiol Infect Dis, 1994; 13:459-67.

Passos XS, Sales WS, Maciel PJ, Costa CR, Miranda KC, LemosJdeA, et al. Candida colonization in intensive care unit patients' urine. MemInstOswaldo Cruz, 2005; 100: 925-8.

Pfaller MA, Jones RN, Doern GV, Fluit AC, Verhoef J, Sader HS, Messer SA, Houston A, Coffman S, Hollis RJ. International surveillance of blood stream infections due to Candida species in the European SENTRY Program: species distribution and antifungal susceptibility including the investigational triazole and echinocandin agents. SENTRY Participant Group (Europe). Diagn Microbiol Infect Dis, 1999; 35: 19-25.

Ragini AK, Sandhya B, Gayatri D, Indumati. Incidence of Non Candida albicans in patients with Urinary Tract Infection with special Reference to speciation and Antifungal Susceptibility. JEMDS, 2012; 1(4): 572-76.

Rashedmarandi F, Rahnamayefarzami M, Saremi M, Sabouri M. A Survey on Urinary Pathogens and their Antimicrobial Susceptibility among Patients with Significant Bacteriuria. Iranian Journal of Pathology, 2008(3);4:191-196.

Sachin C. Deorukhkar, SantoshSaini, and StephenMathew. Non-albicans Candida Infection: An Emerging Threat. Interdisciplinary Perspectives on Infectious Diseases, 2014, Article ID 615958, 7 pages.

Sachin D., Ruchi K., Santosh S. In vitro evaluation of proteinase, phospholipase and haemolysin activities of Candida species isolated from clinical specimens. International Journal of Medicine and Biomedical Research, 2012;1(2):153-157.

Sardi J. C. O., Scorzoni L., Bernardi T., Fusco-Almeida A. M., Mendes Giannini M. J. S. Candida species: current epidemiology, pathogenicity, biofilm formation, natural antifungal products and new therapeutic options. Journal of Medical Microbiology, 2013;62(1):10-24.

Yashavanth R, Shiju M.P, Bhaskar U.A, Ronald R, Anita K.B. Candiduria: Prevalence and Trends in Antifungal Susceptibility in A Tertiary Care Hospital of Mangalore. Journal of Clinical and Diagnostic Research, 2013; 7(11): 2459-2461.

\section{How to cite this article:}

Goyal RK, Sami H, Mishra V, Bareja R, Behara RN. Non-Albicans Candiduria: An Emerging Threat. J App Pharm Sci, 2016; 6 (03): 048-050. 